\title{
Capítulo 10
}

Avaliação de um minicurso sobre o uso de jogos no ensino

Evaluation of a short course on using games in teaching

La evaluación de un curso corto sobre el uso de juegos en la enseñanza

Lya Christina da Costa Brito, licencianda do Curso de Química da Universidade Federal de Goiás (Campus Catalão) e bolsista do Programa Institucional de Bolsa de Iniciação à Docência (Pibid). Endereço: Av. Dr. Lamartine Pinto de Avelar, 1120. CEP: 75704220 - Catalão, GO. Telefone: (64) 3441-5300. E-mail: Iya_cris@ hotmail.com.

Ana Paula Aparecida Borges, licencianda do Curso de Química da Universidade Federal de Goiás (Campus Catalão) e bolsista do Programa Institucional de Bolsa de Iniciação à Docência (Pibid). Endereço: Av. Dr. Lamartine Pinto de Avelar, 1120. CEP: 75704220 - Catalão, GO. Telefone: (64) 3441-5300. E-mail: paula_ borges2010@hotmail.com.

Camila de Oliveira Borges, licencianda do Curso de Química da Universidade Federal de Goiás (Campus Catalão) e bolsista do Programa Institucional de Bolsa de Iniciação à Docência (Pibid). Endereço: Av. Dr. Lamartine Pinto de Avelar, 1120. CEP: 75704-220 - Catalão, GO. Telefone: (64) 3441-5300. E-mail: camilinhaborges89@hotmail.com.

Dayane Graciele dos Santos, bacharel em Ciência da Computação pela Universidade Federal de Goiás (Campus Catalão), licencianda do Curso de Química da Universidade Federal de Goiás (Campus Catalão) e bolsista do Programa de Licenciaturas (Prolicen). 
Endereço: Av. Dr. Lamartine Pinto de Avelar, 1120. CEP: 75704-220 - Catalão, GO. Telefone: (64) 3441-5300. E-mail: dayanegraciele@ yahoo.com.br.

Eloah da Paixão Marciano, licencianda do Curso de Química da Universidade Federal de Goiás (Campus Catalão) e bolsista do Programa Institucional de Bolsa de Iniciação à Docência (Pibid). Endereço: Av. Dr. Lamartine Pinto de Avelar, 1120. CEP: 75704-220 - Catalão, GO. Telefone: (64) 3441-5300. E-mail: eloah_paixao@ hotmail.com.

Simara Maria Tavares Nunes, bacharel e licenciada em Química, mestre e doutora em Ciências pela Faculdade de Filosofia Ciências e Letras de Ribeirão Preto da Universidade de São Paulo, é docente e vice-coordenadora do curso de Licenciatura e Bacharelado em Química da Universidade Federal de Goiás, Campus Catalão, (UFG/CAC) e coordenadora do subprojeto PibidQuímica UFG/CAC. Endereço: Av. Dr. Lamartine Pinto de Avelar, 1120. CEP: 75704-220 - Catalão, GO. Telefone: (64) 3441-5300. E-mail:simaramn@usp.br.

\section{Resumo}

Atualmente, é reconhecida a importância da diversificação dos materiais didáticos para a melhoria dos processos de ensinoaprendizagem. Os jogos didáticos apresentam-se como uma boa alternativa para favorecer esse processo, devido a sua capacidade de impulsionar o aluno a construir ativamente seu aprendizado, em que a construção do conhecimento se dá de maneira prazerosa e motivante. Portanto, devido à necessidade de se instrumentalizarem os futuros professores para a utilização de tais metodologias diferenciadas, como é o caso dos jogos didáticos, buscou-se proporcionar um minicurso sobre o uso de jogos no ensino de Química para os graduandos da Universidade Federal de Goiás - Campus Catalão. Diante dos bons resultados obtidos com a abordagem de jogos no minicurso "Os Jogos e o Lúdico no Ensino de Ciências da Natureza Matemática e suas Tecnologias", este trabalho visa divulgar o potencial alcançado, 
utilizando-se de diversos jogos didáticos abordando vários temas do ensino de Química.

Palavras-chave: Jogos Didáticos. Formação Docente.

\section{Abstract}

The importance of diversification of didactic materials to improve the teaching-learning process is currently recognized. Didactic games are a good alternative for facilitating such a process due to their ability to motivate the student to actively construct knowledge within the context of a friendly environment. Therefore, because of the need to implement and to give support to enable the new generation of teachers to use different methodologies such as didactic games, a short course was provided based on the use of didactic games to teach Chemistry to students at the Universidade Federal de Goiás - Campus Catalão. In light of the good results obtained from the short course "Didactic Games and Ludic Activity in the Natural Sciences, Mathematics and their Technologies", this work aims to disseminate the potential contribution achieved using diverse didactic games covering various topics of Chemistry.

Keywords: Educational Games. Teacher Training.

\section{Resumen}

Actualmente, se reconoce la importancia de la diversificación de los materiales didácticos para el mejoramiento de los procesos de enseñanza y aprendizaje. Los juegos didácticos se presentan como una buena alternativa para favorecer este proceso, debido a su capacidad de estimular el alumno a construir activamente su proprio aprendizaje, en el que la construcción del conocimiento se da de manera placentera y motivadora. Por lo tanto, debido a la necesidad contar con metodologías diferentes, como es el caso de los juegos didácticos, se buscó impartir un curso corto sobre el uso de juegos en la enseñanza de Química para estudiantes de la Universidade Federal de Goiás - Campus Catalão. Frente a los buenos resultados obtenidos con el abordaje de juegos en el curso corto "Los Juegos y el Lúdico en la Enseñanza de Ciencias de Naturaleza Matemática y sus Tecnologías", este trabajo tiene como 
objetivo dar a conocer el potencial alcanzado, utilizando diversos juegos didácticos abordando varios temas de la enseñanza de Química.

Palabras clave: Juegos Didácticos. Formación Docente.

\section{Introdução}

O ensino de Ciências da Natureza deve possibilitar aos alunos a compreensão das transformações químicas que ocorrem no mundo físico para que, por meio dos conhecimentos adquiridos, possam julgar, compreender e participar de forma ativa do que ocorre em sua volta. Para isso, é preciso que o ensino ofereça uma visão global de cada assunto, extrapolando a aquisição de conteúdos, possibilitando a autodescoberta, as atitudes e o exercício de valores, como descrevem os Parâmetros Curriculares Nacionais para o Ensino Médio (PCNEM):

A simples transmissão de informações não é o suficiente para que os alunos elaborem suas idéias de forma significativa. É imprescindivel que o processo de ensino-aprendizagem decorra de atividades que contribuam para que o aluno possa construir e utilizar o conhecimento (BRASIL,1999, p. 93).

A utilização de materiais e recursos didáticos diversificados vem se mostrando um caminho para se atingir as competências exigidas pelas atuais propostas para o ensino médio. Dentre elas, destacamos neste trabalho o uso de atividades lúdicas para promover a construção do conhecimento e motivar o processo de ensino-aprendizagem.

Alguns autores destacam ainda que o objetivo dos jogos ou das atividades lúdicas não se resume apenas em facilitar que o aluno memorize o assunto abordado, mas sim o induza ao raciocínio, à reflexão, ao pensamento crítico e à (re)construção do seu conhecimento (SANTANA; REZENDE, 2008; SOARES, 2004).

Brandes e Phillips (1977, p. 8) relatam de maneira interessante que:

Os jogos podem resolver problemas. Problemas do tipo que se encontram nas relações interpessoais. Podem auxiliar na inadequação social, pois desenvolvem a cooperação nos grupos; podem desenvolver 
a sensibilidade aos problemas dos outros, pois implicam confiança; e promovem a interdependência bem como a independência da identidade pessoal.

O jogo em si permite que o professor, por meio da observação dos alunos em ação (jogando), conheça não só como cada um está lidando com o conteúdo educacional objeto do jogo, mas também perceba os aspectos comportamentais, de liderança, cooperação e ética. Por meio de atividades lúdicas, o professor pode colaborar com a elaboração de conceitos; reforçar conteúdos; promover a sociabilidade entre os alunos; e trabalhar a criatividade, o espírito de competição e a cooperação (FIALHO, 2008).

Segundo Elkonin (1998), o jogo pode ser uma oportunidade de entrosamento entre aluno e professor como forma de enriquecimento e motivação para a aprendizagem. É uma atividade em que se reconstroem as relações sociais e, embora sejam aplicados com uma grande variedade de temas, todos eles contribuem, por princípio, ao mesmo conteúdo: a atividade do homem e as relações sociais entre as pessoas:

Medianteo jogo didático,vários objetivos podem ser atingidos, relacionados à cognição (desenvolvimento da inteligência e da personalidade, fundamentais para a construção de conhecimentos); afeição (desenvolvimento da sensibilidade e da estima e atuação no sentido de estreitar laços de amizade e afetividade); socialização (simulação de vida em grupo); motivação (envolvimento da ação, do desafio e mobilização da curiosidade) e criatividade (MIRANDA, 2001, p. 64).

Como sugere Kishimoto (1996), o professor deve rever a utilização de propostas pedagógicas, passando a adotar em sua prática aquelas que atuem nos componentes internos da aprendizagem, já que estes não podem ser ignorados quando o objetivo é a apropriação de conhecimentos por parte do aluno e a formação cidadã dele.

De acordo com os PCN (BRASIL, 1996, p. 28),

[...] cabe o professor selecionar, organizar e problematizar os conteúdos de modo a possibilitar um avanço intelectual do aluno [...] é importante que o professor tenha claro que o Ensino de Ciências não se resume na 
apresentação de definições cientificas, como em muitos livros didáticos, em geral fora da compreensão dos alunos.

Assim, o processo de globalização passa a exigir a formação de um profissional da educação com capacidade de adaptação às inovações tecnológicas em permanente processo de atualização (SILVA e OLIVEIRA, 2005). No plano legal, tais mudanças têm sustentação na própria Lei de Diretrizes e Bases da Educação Nacional (BRASIL, 1996), que, no artigo 36, define que cabe ao currículo do ensino médio adotar metodologias de ensino e de avaliação que estimulem a iniciativa dos estudantes.

Visando essas perspectivas, o objetivo deste trabalho é proporcionar um espaço coletivo de reflexão sobre a docência e a instrumentalização de futuros professores para a inovação do ensino com a apresentação e a discussão de jogos que possam facilitar o entendimento dos mais diversos conteúdos de Química trabalhados em sala de aula, como também dinamizar suas aulas por meio da elaboração e da aplicação de práticas pedagógicas diversificadas, como é o caso dos jogos didáticos. O objetivo é também fazer com que os futuros professores possam se inspirar nos jogos apresentados e elaborar seus próprios jogos, de acordo com a necessidade e o nivel de conhecimento de seus alunos. Como sugerem Barros e Santos (2009), os professores devem buscar alternativas para tornar a disciplina mais compreensivel, tal como a contextualização dos assuntos, mostrando a importância da Química nos avanços científicos e tecnológicos que afetam diretamente a sociedade.

Para tanto, as bolsistas do Programa Institucional de Bolsa de Iniciação à Docência (Pibid) do curso de Licenciatura em Química da Universidade Federal de Goiás/Campus Catalão (UFG/CAC) propuseram e ofereceram o minicurso "Os Jogos e o Lúdico no Ensino de Ciências da Natureza, Matemática e suas Tecnologias", realizado nos dias 21 a 23 de outubro de 2009 durante a VI Semana Nacional de Ciências e Tecnologia, o V Simpósio de Ensino, Pesquisa, Extensão e Cultura e o IV Fórum de C\&T do Cerrado SBPC/GO.

O curso teve como principais objetivos: i) divulgar a utilização de recursos didáticos alternativos que possam propiciar a construção 
do conhecimento de forma significativa, lúdica e prazerosa, utilizandose para isso dos jogos didáticos; ii) oportunizar aos licenciandos das diversas áreas o contexto teórico-prático da metodologia dos jogos; e iii) discutir o uso de jogos didáticos para a facilitação do processo de ensino-aprendizagem, além de estimular o seu uso.

Com o objetivo de avaliar o impacto das ações do minicurso nos participantes, foi utilizada a pesquisa qualitativa, tendo como instrumento de coleta de dados questionários semiestruturados.

\section{Metodologia}

Com o propósito de apresentar aos licenciandos a forma de se utilizar os jogos didáticos no ensino e suas contribuições para a aprendizagem significativa dos alunos do ensino médio, as bolsistas do Programa Institucional de Bolsa de Iniciação à Docência (Pibid), do curso de Licenciatura em Química da Universidade Federal de Goiás /Campus Catalão (UFG/CAC), ofereceram um minicurso para os graduandos da UFG/CAC. A proposta foi fomentar a discussão sobre como se trabalhar os jogos didáticos em sala de aula. Para tanto, propiciou-se um ambiente de discussão e reflexão dos participantes a respeito dos momentos de condução de atividades dessa natureza, bem como a reflexão sobre as possibilidades pedagógicas de sua utilização. Além disso, buscou-se promover o contato direto dos participantes com a prática dos jogos didáticos, de modo que eles mesmos pudessem avaliar as potencialidades desse recurso pedagógico.

Para tanto, o minicurso foi dividido em dois momentos: em um primeiro momento, foi realizada uma contextualização teórica sobre o uso de jogos no ensino, explicitando seu potencial lúdico e educativo, além de se descrever suas contribuições para o desenvolvimento de competências e habilidades para uma formação cidadã. Em uma segunda etapa, foi proposta a apresentação e análise de alguns jogos didáticos para o ensino de Química. Assim, os participantes do minicurso puderam se colocar no lugar de alunos do ensino médio e experienciar e avaliar o uso dessa metodologia diferenciada de ensino. 
Os jogos apresentados no minicurso "Os Jogos e o Lúdico no Ensino de Ciências da Natureza, Matemática e suas Tecnologias" se destinaram a ilustrar situações em que houvesse o envolvimento dos alunos de forma mais dinâmica e que pudessem proporcionar um melhor aprendizado dos conteúdos químicos, além de buscarem propiciar uma abordagem interdisciplinar e social temática. 0 objetivo foi mostrar que tais recursos proporcionam a possibilidade de os alunos aprenderem a argumentar, expor suas ideias e compartilhar o conhecimento, adquirir espírito de equipe e, assim, proporcionar uma melhor relação aluno-aluno e aluno-professor. Como sugerem Soares, Okumura e Cavalheiro (2003), o desenvolvimento de estratégias modernas e simples, utilizando experimentos, jogos e outros recursos didáticos, é recomendado para dinamizar o processo de aprendizagem em Química.

Foram apresentados os seguintes jogos didáticos e suas respectivas abordagens (Tabela 1).

Tabela 1. Jogos didáticos apresentados no minicurso "Os Jogos e o Lúdico no Ensino de Ciências da Natureza, Matemática e suas Tecnologias"

\begin{tabular}{|l|l|}
\hline \multicolumn{1}{|c|}{ Nome do jogo } & \multicolumn{1}{c|}{ Conteúdo abrangido } \\
\hline Na Trilha da Reciclagem & Educação Ambiental \\
\hline Jogo das Ligações & Ligações Químicas \\
\hline $\begin{array}{l}\text { O Desafio da Tabela } \\
\text { Periódica }\end{array}$ & Tabela Periódica e aplicação dos elementos químicos \\
\hline $\begin{array}{l}\text { Construindo com } \\
\text { Funções Orgânicas }\end{array}$ & $\begin{array}{l}\text { Nomenclatura, estrutura e aplicação de compostos } \\
\text { orgânicos }\end{array}$ \\
\hline
\end{tabular}

Cada um dos jogos foi apresentado aos participantes, explicitando suas regras, seus conteúdos químicos e sociais envolvidose os objetivos do jogo. A partir daí, os participantes tinham a oportunidade de jogar para avaliarem por si mesmos o potencial lúdico e pedagógico de cada um dos jogos. Durante o minicurso, os participantes, além de adquirir novos conhecimentos, tiveram a possibilidade de dialogar, o que proporcionou uma troca de experiências entre eles, levando a uma reflexão sobre a teoria e a prática. 
A repercussão das metodologias apresentadas junto aos participantes foi avaliada por meio de abordagem qualitativa, utilizando-se como instrumentos de coleta de dados questionários aplicados antes e após as atividades. A pesquisa qualitativa atua em niveis de realidade em que dados trazem à tona indicadores e tendências observáveis. A abordagem qualitativa realça os valores, as crenças, as representações, as opiniões e as atitudes e usualmente é empregada para que o pesquisador compreenda os fenômenos caracterizados por um alto grau de complexidade interna do fenômeno pesquisado (DEMO, 1995). Contudo, a abordagem qualitativa não exclui a quantitativa.

Segundo Bogdan e Biklen (1994, p. 195),

[...] embora os dados quantitativos recolhidos por outras pessoas (avaliadores, administradores outros investigadores) possam ser convencionalmente úteis tal como foram descritos, os investigadores qualitativos dispõem-se na recolha de dados quantitativos de forma crítica. Não é que os números por si não tenham valor. Em vez disso, o investigador qualitativo tende a visar o processo de compilação na sua cabeça perguntando-se o que os números dizem acerca das suposições das pessoas que os usam e os compilam [...] os investigadores qualitativos são inflexíveis em não tornar os dados quantitativos por seu valor facial.

\section{Resultados e discussões}

Nos dias atuais, a busca pela qualificação profissional está cada vez mais presente na vida dos professores. Assim, palestras, minicursos e outros representam importantes momentos para que ocorra essa qualificação. O resultado de uma formação inadequada dos professores é um distanciamento progressivo dos atuais referenciais para um ensino de qualidade, com a utilização de metodologias e recursos didáticos diversificados. É fundamental que o professor saiba analisar de modo crítico como utilizar, aprimorar ou desenvolver materiais didáticos para um significativo processo de ensino-aprendizagem. Assim, para que inovações metodológicas possam ser incorporadas de 
forma efetiva à prática pedagógica, é necessário que os professores as conheçam e reconheçam seus potenciais pedagógicos.

Pensando nisso, este trabalho se propõe a relatar uma experiência desenvolvida pelos bolsistas do Programa Institucional de Bolsa de Iniciação a Docência (Pibid), ao ministrarem um minicurso sobre o uso do lúdico no ensino, cuja proposta era motivar os participantes para a utilização de metodologias diferenciadas no ensino.

Participaram do minicurso "Os Jogos e o Lúdico no Ensino de Ciências da Natureza, Matemática e suas Tecnologias" um total de 22 graduandos, com faixa etária entre 18 e 39 anos (Tabela 2), que avaliaram os jogos aplicados por meio de opinários, sendo 50\% do sexo feminino e 50\% do sexo masculino, pertencentes aos cursos de Ciências Biológicas (31\%), Matemática (27\%), Química (18\%), Engenharia de Minas (9\%), Administração (5\%), Enfermagem (5\%) e Física (5\%).

Tabela 2. Faixa etária dos participantes do minicurso "Os Jogos e - Lúdico no Ensino de Ciências da Natureza, Matemática e suas Tecnologias"

\begin{tabular}{|c|c|c|c|c|c|c|c|c|}
\hline Idade & $\begin{array}{c}17 \\
\text { anos }\end{array}$ & $\begin{array}{c}18 \\
\text { anos }\end{array}$ & $\begin{array}{c}19 \\
\text { anos }\end{array}$ & $\begin{array}{c}20 \\
\text { anos }\end{array}$ & $\begin{array}{c}\mathbf{2 1} \\
\text { anos }\end{array}$ & $\begin{array}{c}\mathbf{2 2} \\
\text { anos }\end{array}$ & $\begin{array}{c}\text { Acima } \\
\text { de } 25\end{array}$ & $\begin{array}{c}\text { Não } \\
\text { responderam }\end{array}$ \\
\hline & $5 \%$ & $10 \%$ & $14 \%$ & $10 \%$ & $14 \%$ & $10 \%$ & $14 \%$ & $18 \%$ \\
\hline
\end{tabular}

De acordo com as respostas obtidas nos opinários, a expectativa inicial dos participantes em relação ao minicurso era conhecer novas metodologias de ensino, principalmente o uso de jogos didáticos, por ser uma abordagem que pode despertar o interesse dos alunos em sala de aula, ao tornar a aula mais atrativa e agradável, como também desenvolver, a partir dos jogos apresentados, outros jogos que possam ser adaptados para as várias áreas de ensino: “[...] espero que seja uma atividade interativa e empolgante”; “[...] ganhar uma nova maneira de despertar o interesse em ensinar e aprender"; “[...] novas técnicas para trabalhar com os alunos". A busca por novas metodologias e estratégias de ensino para a motivação da aprendizagem, que sejam acessiveis, modernas e de baixo custo, é sempre um desafio para os professores (ROSA; ROSSI, 2008; BRASIL, 2006). 
Segundo Menezes (2003, p. 6), "os professores buscam mudar suas práticas, mas faltam condições para dar estabilidade a essas mudanças". Assim, esse minicurso buscou implementar um apoio aos futuros professores para o conhecimento e aprendizado de novas tecnologias e novos recursos pedagógicos.

Os participantes citaram também nos opinários a oportunidade de vivenciar na prática as novas metodologias de ensino, vistas por eles somente na literatura. Segundo Lôbo e Moradillo (2003, p. 39), as "concepções que nós temos, nossas preferências pessoais e estilos pedagógicos desempenham um papel decisivo na prática docente". Para Porlán e Rivero, "saber algo não é sinônimo de saber fazê-lo na prática” (1998, p. 8), o que nos faz refletir que, quando se busca uma formação profissional qualificada, os conhecimentos adquiridos durante a formação acadêmica são fundamentais, mas precisam estar integrados com a prática, com a experiência e, principalmente, com a possibilidade de enfrentar e resolver problemas reais (RAMOS et al., 2005).

Dentre os participantes, $100 \%$ afirmaram gostar de participar do minicurso pela forma divertida de rever os conceitos químicos inseridos nos quatro jogos apresentados. Quando perguntados sobre a possibilidade do uso de jogos didáticos despertarem o interesse dos alunos, 100\% afirmaram ser relevante a aplicação desses recursos didáticos, sendo os jogos interessantes pelo ponto de vista lúdico e pedagógico. Quanto à construção do conhecimento, 96\% concordaram que os jogos apresentados ajudam na construção do conhecimento químico.

Lara (2004) afirma que os jogos didáticos vêm ganhando espaço dentro das escolas, em uma tentativa de trazer o lúdico para dentro da sala de aula. Acrescenta-se que a pretensão da maioria dos professores com a sua utilização é tornar as aulas mais agradáveis, com o intuito de fazer com que a aprendizagem torne-se algo mais fascinante. "[...] Os jogos são mais que simples exercícios. Oportuniza ao aluno criar estratégias, aprender a ser crítico e confiante em si mesmo, não apenas a pensar, mas incentiva a troca de idéias, contribuindo para o desenvolvimento da autonomia" (VALENTE, 2005, p. 2). 
Ao serem questionados sobre o uso dos jogos didáticos para facilitar a aprendizagem, $87 \%$ dos entrevistados concordaram que a construção do conhecimento dessa forma se torna menos desgastante e mais agradável, enquanto $4 \%$ discordaram sobre os benefícios dos jogos e $9 \%$ se mostraram indiferentes ao questionamento.

Houve ainda comentários sobre o uso dos jogos para a avaliação do conteúdo teórico trabalhado em sala de aula: "[...] coloca em prática o que foi aprendido em sala de aula, observando se houve entendimento ou não"; “[...] o uso de jogos didáticos dinamiza o ensino tornando-o mais prazeroso e motivador para os alunos". Assim, essa ferramenta favorece a aprendizagem e estimula o desenvolvimento de diversas habilidades, como a integração e a socialização (SANTOS et al., 2009).

Sobre a viabilidade da aplicação dos jogos em sala de aula, $100 \%$ dos entrevistados disseram estar de acordo quanto à promoção do ensino-aprendizagem por meio dos jogos apresentados, pois o uso de materiais didáticos alternativos pode tornar a aula mais atraente e agradável, por sair da rotina giz-quadro negro.

Conforme Silveira e Barone (1998, p. 2), com os jogos didáticos o aprendizado torna-se mais empolgante e pode ser uma nova forma de se obter conhecimento:

[...] os jogos podem ser empregados em uma variedade de propósitos dentro do contexto de aprendizado. Um dos usos básicos e muito importantes é a possibilidade de construir-se a autoconfiança. Outro fator é o incremento da motivação [...] um método eficaz que possibilita uma prática significativa daquilo que está sendo aprendido. Até mesmo o mais simplório dos jogos pode ser empregado para proporcionar informações factuais e praticar habilidades, conferindo destreza e competência.

Quanto à preferência dos jogos aplicados, 32\% dos participantes afirmaram ter gostado mais do jogo "Na Trilha da Reciclagem", por considerarem-no educativo, interessante e de fácil compreensão, como também por abordar conceitos envolvidos no cotidiano, o que facilitou a compreensão de todos, independentemente da idade e do curso, o que era esperado por se tratar de um jogo com caráter interdisciplinar. 
Os jogos "Construindo com Funções Orgânicas" e "Jogo das Ligações" obtiveram cada um $28 \%$ da preferência dos entrevistados; 0 interesse demonstrado pelo jogo "Construindo com Funções Orgânicas" foi justificado como sendo pela dinâmica e competitividade exigidas pelo mesmo. 0 jogo "Desafio da Tabela Periódica" teve a aprovação de 18\% dos entrevistados, que apontaram como característica interessante do jogo a sua fácil aplicação em sala de aula, como também a possibilidade de adaptação para outras áreas de ensino: “[...] Gostei muito de 'O Desafio da Tabela Periódica' [...] é ótimo e de fácil aplicação" (aluna do curso de Química); “[...] na 'Trilha da Reciclagem', porque é um jogo interessante e educativo" (aluno do curso de Ciências Biológicas); “[...] Gostei de 'Construindo com Funções', pois ele foi mais dinâmico e animado" (aluno do curso de Matemática).

Um passo importante na formação do professor é o estimulo à renovação e à adaptação das atividades experimentais a que foi exposto: "[...] é fundamental que o professor analise de modo crítico como utilizar, aprimorar e/ou desenvolver materiais didáticos adaptados a sua própria realidade, para que as inovações possam ser incorporadas de forma efetiva à rotina de ensino" (LORETO; SEPEL, 2006).

A Figura 1 mostra os participantes do minicurso "Os Jogos e o Lúdico no Ensino de Ciências da Natureza, Matemática e suas Tecnologias" em ação.

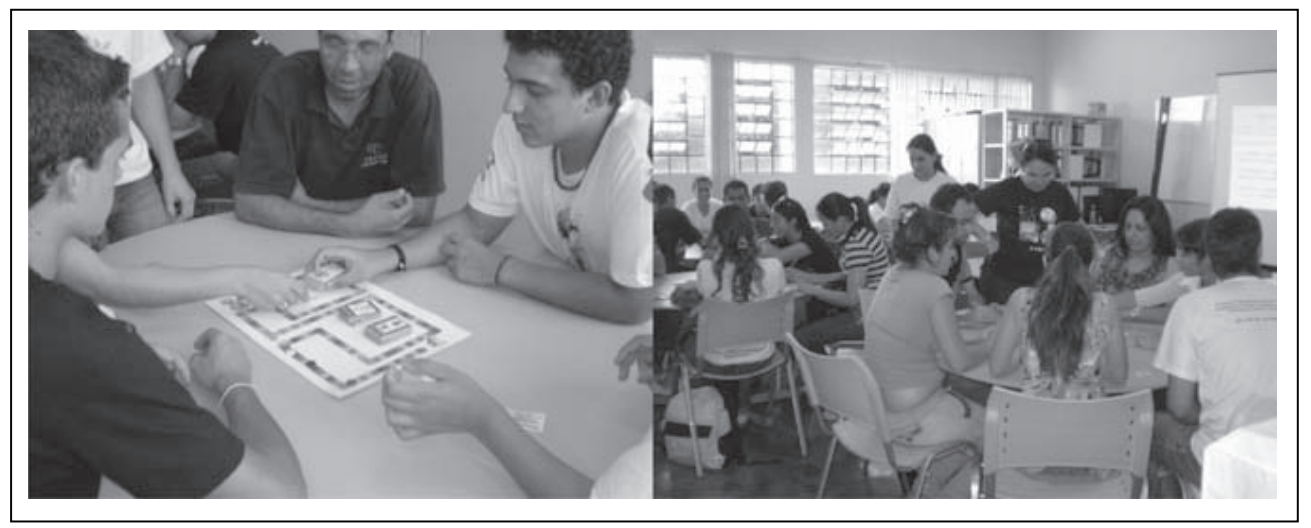

Figura 1. Fotos do minicurso "Os Jogos e o Lúdico no Ensino de Ciências da Natureza, Matemática e suas Tecnologias" 
Quanto ao que deveria ser melhorado no minicurso, 50\% consideraram-no bom e afirmaram que nada precisaria ser melhorado, enquanto $28 \%$ dos entrevistados sugeriram algumas modificações, descritas na Tabela 3.

\section{Tabela 3. Modificações sugeridas para os jogos}

\begin{tabular}{|c|c|c|c|c|}
\hline $\begin{array}{c}\text { Modificações } \\
\text { sugeridas }\end{array}$ & $\begin{array}{c}\text { Mais } \\
\text { competição no } \\
\text { desenvolvimento } \\
\text { dos jogos }\end{array}$ & $\begin{array}{c}\text { Mais relação com } \\
\text { o cotidiano }\end{array}$ & Prêmios & $\begin{array}{c}\text { Não } \\
\text { opinaram }\end{array}$ \\
\hline & $14 \%$ & $9 \%$ & $5 \%$ & $22 \%$ \\
\hline
\end{tabular}

Com os resultados obtidos por meio dos opinários, pôde-se perceber a importância da divulgação de jogos didáticos não apenas restrita à área de licenciatura em Ciências, como também nas demais áreas que participaram do minicurso, visto que, apesar de os jogos serem direcionados à área de Química, houve despertar de interesse de todos, visto o esforço e a dedicação observados em se apreender jogando. A descontração e o prazer de aprender brincando facilitou o processo de ensino-aprendizagem, percebido pelos comentários: “[...] ano que vem tem de novo? Foi o melhor minicurso, quero fazer outra vez"; "[...] os jogos estão muito bons, nunca fui a um minicurso tão divertido”; “[...] gostei muito do último jogo 'Construindo com Funções', ele é muito competitivo, tem que ter ano que vem de novo".

O fato de o minicurso ter sido oferecido para licenciandos de diferentes áreas também foi um ponto de destaque, por favorecer a interação e um clima de troca de experiências e de discussões interdisciplinares, favorecendo a formação de sujeitos ativos na construção do seu conhecimento.

Jogos como "Na Trilha da Reciclagem" e "O Desafio da Tabela Periódica" foram avaliados como de fácil compreensão pelos participantes, por se restringirem a um nivel de conhecimento razoável de Química. Já nos jogos "Jogo das Ligações” e "Construindo com Funções", só se percebe a exploração máxima dos jogos se os alunos tiverem desenvolvido noções completas de Ligações Químicas e Química Orgânica, respectivamente, o que acontece não apenas com o uso de jogos didáticos, mas também por meio de aulas teóricas e outros recursos didáticos, o que acabou se tornando um desafio para 
os participantes que não se recordavam do que haviam aprendido no ensino médio.

Segundo Freire (2004, p. 22),

é preciso que o formando, desde o principio da sua experiência formadora, assuma-se como sujeito também da produção do saber, se convença definitivamente de que ensinar não é transmitir saberes, mas criar as possibilidades para a sua produção ou a sua construção.

Para Valente (1993), existe uma grande variedade de jogos didáticos para ensinar conceitos que podem ser difíceis de serem compreendidos pelo fato de não existirem aplicações práticas mais imediatas.

É no processo do confronto de idéias que o aluno terá oportunidade de aprimorar suas concepções e se aproximar cada vez mais do mundo da Química. Ao longo da história, essa é a forma como a ciência se desenvolve. Por isso, não há que se temer os erros, mas sim aprender a conviver com eles e a superá-los (LIMA, 1996, p. 2).

A partir dos resultados obtidos, pode-se afirmar quea introdução de jogos no cotidiano escolar é muito importante, devido à influência que eles exercem nos alunos, pois quando eles se encontram envolvidos emocionalmente na ação, torna-se mais fácil e dinâmico o processo de ensino-aprendizagem. Isso foi claramente observado no presente minicurso, ao se apresentar os jogos aos futuros professores.

Assim, para que essa mudança ocorra, é preciso que haja uma mudança nas concepções de ensino-aprendizagem dos professores, a fim de que eles reflitam sobre os diferentes métodos de ensino. Percebe-se que esse tipo de minicurso contribui para a qualificação docente na medida em que possibilita a discussão da prática e de novas estratégias de ensino. Além disso, percebe-se que esse espaço consegue levantar e discutir questões que permeiam a ação e sensibiliza de alguma forma a maioria dos participantes, mas é impossível prever se eles transformarão sua forma de atuação docente. Porém, esperase que isso seja efetivado, em prol de uma melhoria no processo de ensino-aprendizagem, fazendo com que os participantes reflitam sobre o ensino que pretendem levar a seus alunos. 


\section{Conclusões}

Inegavelmente, o professor,como todo profissional, precisa estar atualizado para atuar na escola de seu tempo. Isso implica a necessária atualização quanto aos atuais recursos pedagógicos disponiveis na atualidade para auxiliar no processo de ensino-aprendizagem. Os jogos pedagógicos são um desses recursos pedagógicos que tanto podem contribuir para a melhoria da qualidade da educação, daí a importância e a relevância do minicurso aqui relatado.

Os participantes do minicurso "Os Jogos e o Lúdico no Ensino de Ciências da Natureza, Matemática e suas Tecnologias" entenderam a importância de tal atividade, voltada para uma atualização profissional e para a melhoria de sua formação inicial. O uso dos jogos como método de ensino para os temas Educação Ambiental; Tabela Periódica e Aplicações dos Elementos; Ligações Químicas e Nomenclatura; e Estrutura e Aplicação de Compostos Orgânicos mostrou-se uma excelente ferramenta de ensino, pela sua fácil confecção e aplicação em sala de aula. A possibilidade de adaptação dos jogos a outros temas, como também sua possibilidade de extrapolação para níveis mais difíceis, utilizando-se da interdisciplinaridade, demonstram a eficiência de tais recursos didáticos no ensino.

A função educativa dos jogos foi facilmente observada durante a sua aplicação, verificando-se que ele favorece a construção de conhecimentos em clima de alegria e prazer. O jogo oferece estímulo e o ambiente necessários para propiciar o desenvolvimento espontâneo e criativo dos alunos, além de permitir que o professor amplie seus conhecimentos sobre técnicas significativas e diferenciadas de ensino e desenvolva suas capacidades pessoais e profissionais, estimulando-o a recriar sua própria prática pedagógica (BRASIL, 1999).

Assim, entende-se que o processo de desenvolvimento profissionaldoprofessordeveassentar-sesobumaboabasepedagógica, que the permita a utilização e ampliação de suas metodologias e de estratégias de ensino. Portanto, cabe ao professor organizar suas aulas, propor aos seus alunos variadas formas de obtenção do conhecimento, trabalhando com recursos didáticos diversos, como é o caso dos jogos didáticos, tornando assim as aulas mais motivadoras e dinâmicas. 
Há praticamente um consenso entre pesquisadores de que as concepções dos professores de Ciências, suas crenças e suas epistemologias têm uma influência marcante sobre as suas práticas pedagógicas e sobre as concepções dos alunos (LÔBO; MORADILLO, 2003). Assim, a participação em minicursos como esse é importante por oferecer alternativas para modificar a forma de ensinar, pois proporciona ao educador uma nova visão de como se trabalhar os conteúdos, valorizando a vivência do aluno, resgatando a sua autonomia e seu conhecimento prévio, por meio do trabalho com jogos e situações que realmente sejam interessantes para os alunos.

Por fim, sugere-se que os professores incorporem os jogos didáticos às suas práticas pedagógicas, por ser uma ferramenta didática importante no auxílio do processo de ensino e aprendizagem, além de desenvolver aspectos comportamentais saudáveis e motivar os alunos. Como sugere Fialho (2008), a exploração do aspecto lúdico pode tornar-se uma técnica facilitadora na elaboração de conceitos, no reforço de conteúdos, na sociabilidade entre os alunos, na criatividade e no espírito de competição e cooperação, tornando esse processo transparente ao ponto em que o domínio sobre os objetivos propostos na obra seja assegurado.

Nesse sentido, espera-se que os professores e as escolas tenham as condições físicas e de infraestrutura de apoio para a concretização das inovações tão necessárias ao atual ensino.

\section{A confecção dos jogos}

\section{Jogo: "Na Trilha da Reciclagem"}

O jogo é composto por uma trilha (tabuleiro), confeccionada em papel vergê; um dado (também confeccionado em papel vergê); peões de cores distintas para identificar cada jogador (foram utilizados botões coloridos); 18 "Cartas do Bem"; 18 "Cartas do Mal"; 20 cartas "Hora de Saber +". Todas as cartas foram confeccionadas em papel vergê e plastificadas com papel contact (Figura 2). 


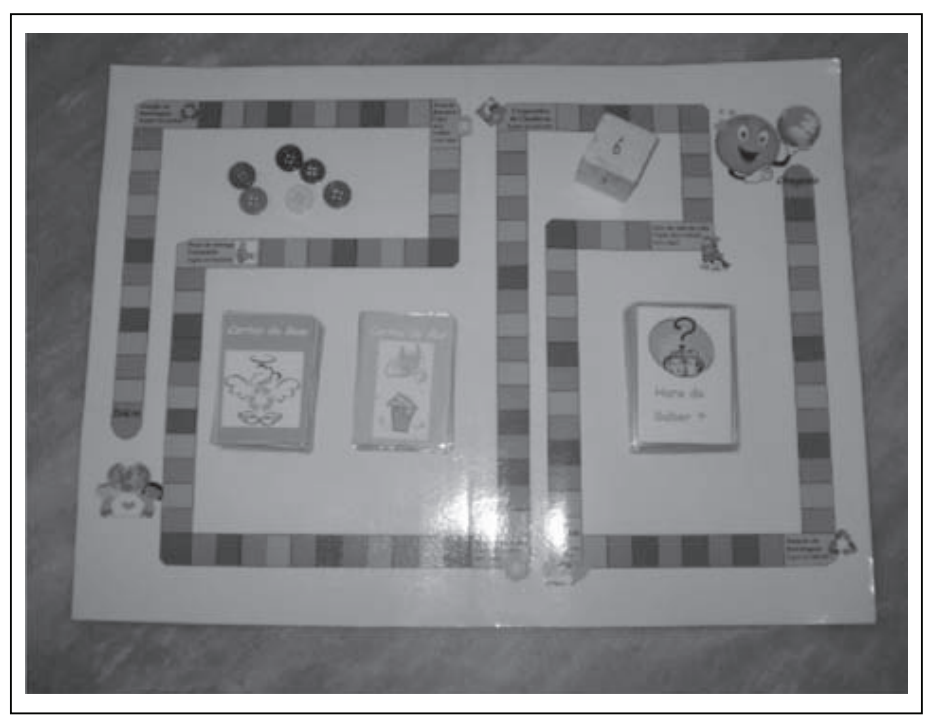

Figura 2. Foto do tabuleiro, dos dados, peões e das cartas do jogo "Na Trilha da Reciclagem"

Recomenda-se que esse jogo seja utilizado, preferencialmente, por até seis jogadores ou seis equipes. No começo do jogo, todos os jogadores devem estar na posição "Início". Depois de decidida a ordem de jogada, o primeiro jogador joga o dado e deve andar com o peão exatamente o número de casas que sorteou. Sempre que o peão cair sobre uma casa verde, o jogador deve sortear uma "Carta do Bem”, ler em voz alta e seguir suas instruções. As “Cartas do Bem” trazem atitudes corretas em relação ao tratamento do lixo, à coleta seletiva e à reciclagem e, como benefício, o jogador pode avançar algumas casas a mais na trilha. A Figura 3 apresenta uma das “Cartas do Bem” utilizada no jogo.
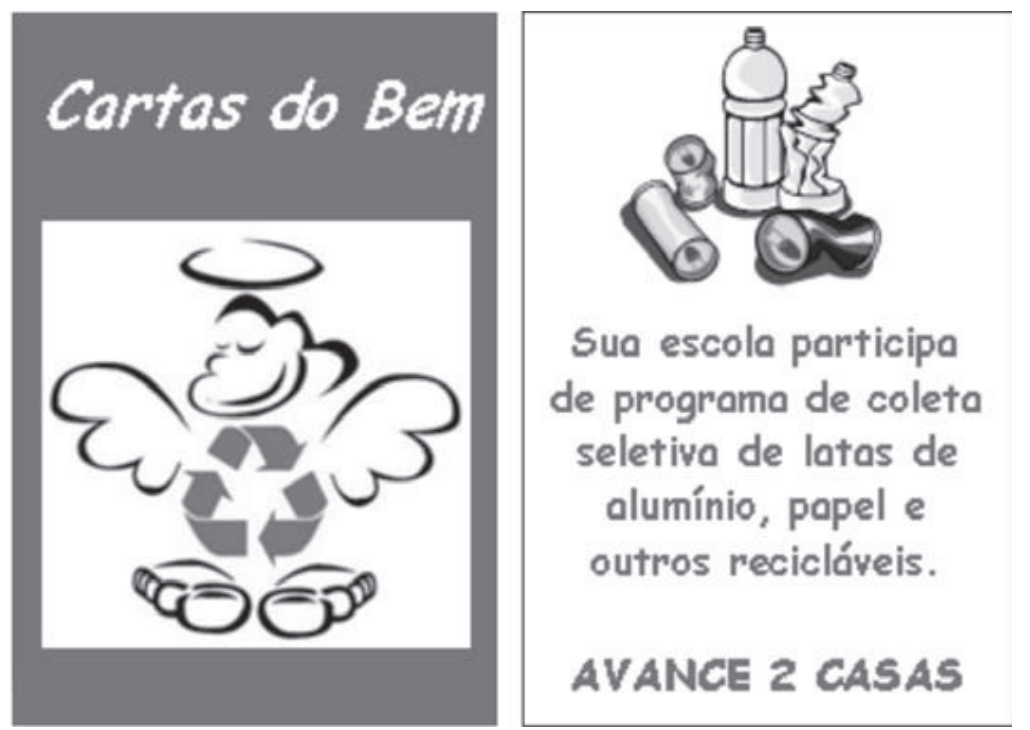

Figura 3. Exemplo do verso e da frente de uma "Carta do Bem" 
Se o peão cair sobre uma casa vermelha, o jogador deve sortear uma "Carta do Mal”, ler em voz alta e seguir suas instruções. As "Cartas do Mal" contêm atitudes incorretas em relação ao tratamento do lixo, à reciclagem e à coleta seletiva e trazem penalidades para o jogador, como, por exemplo, retroceder algumas casas. Na Figura 4, temos o exemplo de uma das “Cartas do Mal” utilizada no jogo.
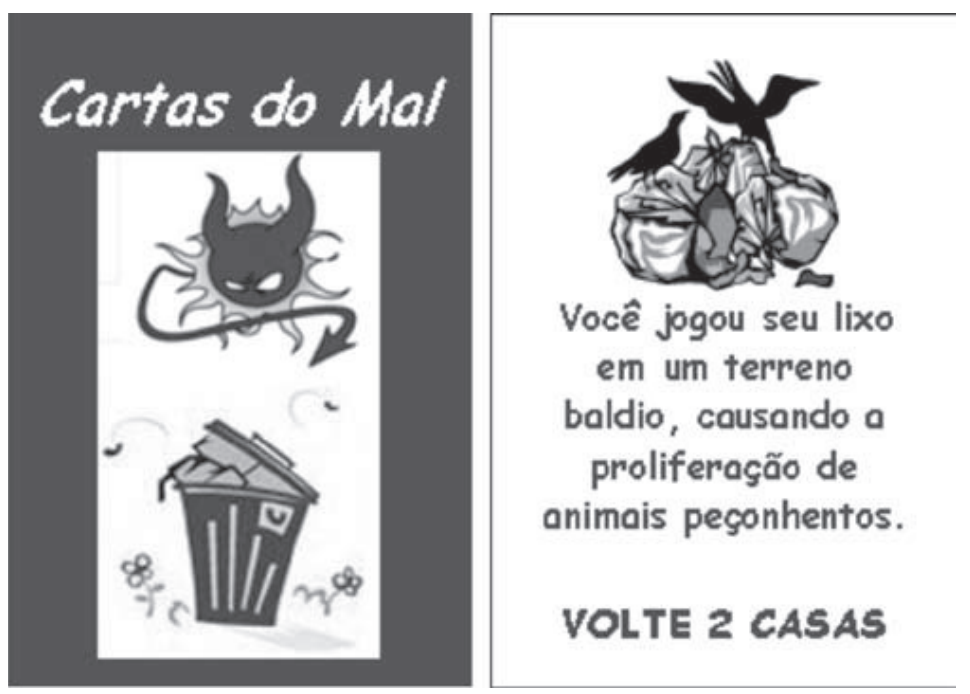

Figura 4. Exemplo do verso e da frente de uma "Carta do Mal"

Quando o peão cair em uma casa amarela, o jogador deve sortear uma carta "Hora de Saber +". Essas cartas trazem perguntas referentes ao tratamento do lixo, que devem ser lidas e respondidas em voz alta (exemplo na Figura 5). Quando o peão cair em casas azuis, nenhum beneficio ou penalidade é concedido e a vez de jogar é do próximo jogador.
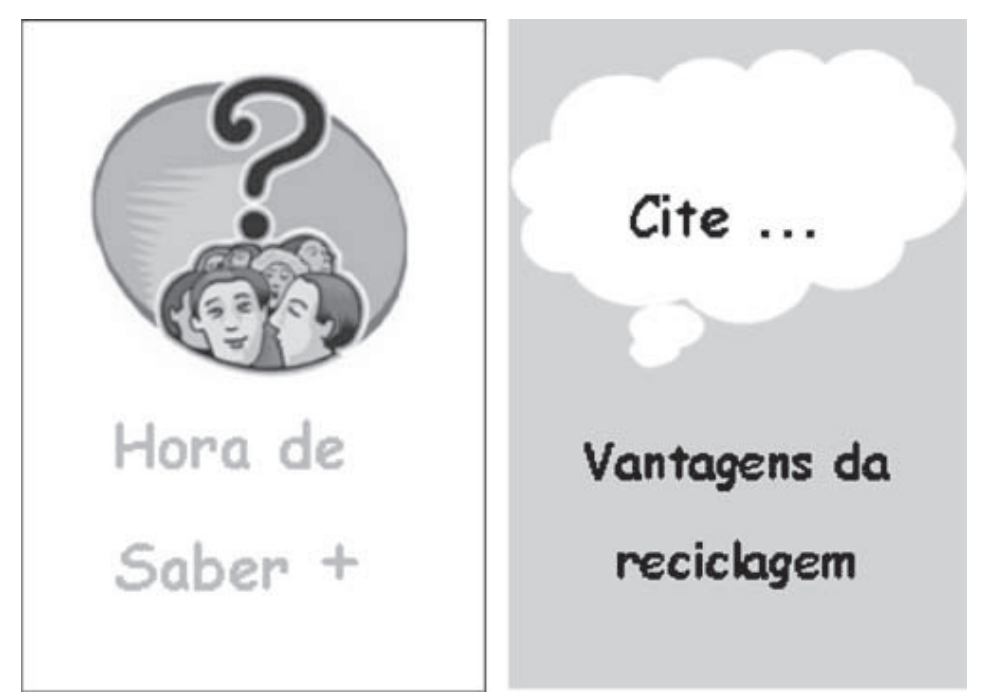

Figura 5. Exemplo do verso e da frente de uma carta "Hora de Saber +" 
A trilha (apresentada na Figura 6) também contém áreas em lilás que trazem benefícios ou penalidades para o jogador. Se o peão cair na casa "Área de Descanso" ou "Lixo na Sala de Aula", o jogador deve ficar uma rodada sem jogar. Se, por sua vez, o peão cair na casa "Estação de Reciclagem”, "Ponto de Entrega Voluntária”, "Cooperativa de Catadores" ou "Seção Aprenda", o jogador poderá jogar o dado novamente.

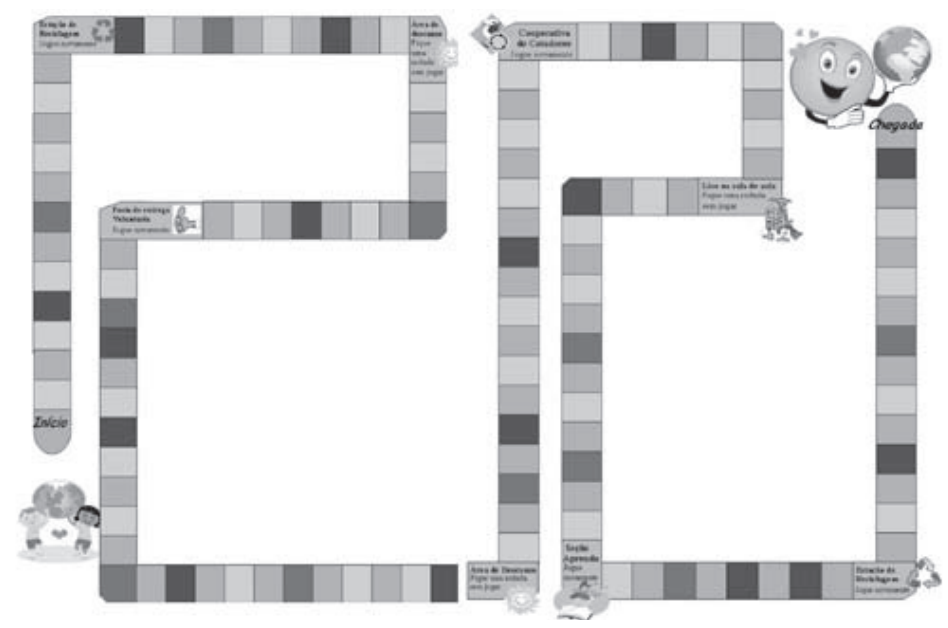

Figura 6. Trilha do jogo "Na Trilha da Reciclagem"

Sempre que o jogador sortear uma carta, deve voltá-la para o final do monte. O primeiro jogador que chegar ao fim da trilha será o ganhador. Os demais jogadores podem continuar a jogar para determinar as demais posições.

\section{Jogo: "O Desafio da Tabela Periódica"}

O jogo “O Desafio da Tabela Periódica” é composto por 40 cartas contendo propriedades físicas e químicas (elétrons, massa atômica e pontos de fusão e ebulição), além de conter o nome e o símbolo de um elemento químico e suas aplicações no cotidiano. As cartas foram confeccionadas em papel vergê e plastificadas com papel contact (Figura 7). 


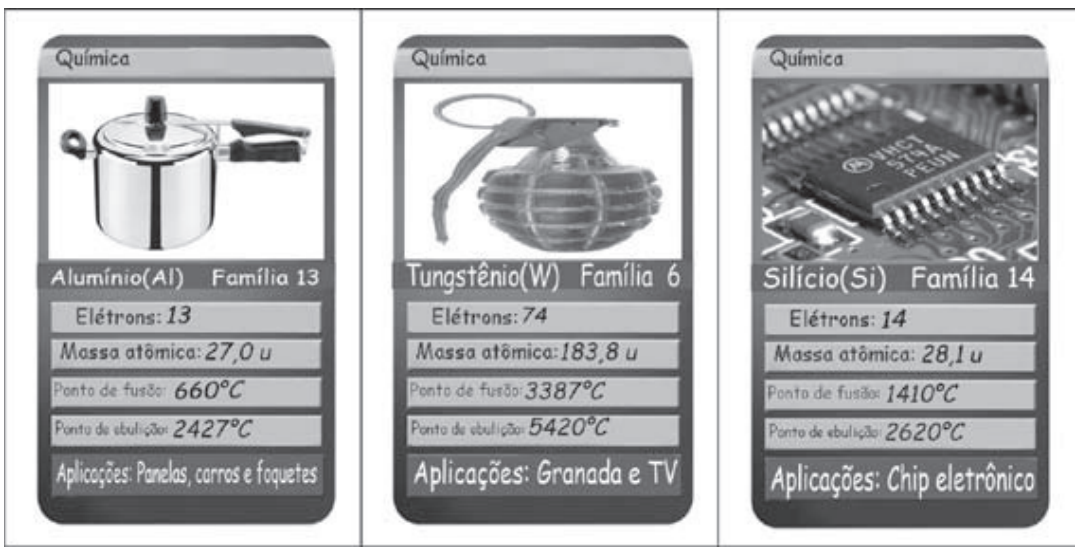

Figura 7. Cartas do jogo "O Desafio da Tabela Periódica”

O jogo comporta de dois a 10 jogadores, que devem estar dispostos em círculos, em que cada um deve ter o mesmo número de cartas. Assim, o jogo é realizado com baralho fechado, isto é, cada jogador tem que jogar com a primeira carta do seu baralho. 0 início do jogo se dá quando um dos jogadores escolhe uma carta do seu baralho, quando vai analisar as características dos elementos químicos e escolherá uma das propriedades físicas ou químicas para comparar com a dos adversários; quem tiver o maior valor nas propriedades, ganha as cartas da rodada.

\section{Jogo: "Jogo das Ligações Químicas"}

O jogo é composto por um baralho contendo 68 cartas confeccionadas em papel vergê e plastificadas com papel contact. O baralho contém cartas que representam: a) ligações covalentes; b) ligações iônicas; c) elementos químicos, com suas respectivas distribuições eletrônicas e valências; e d) compostos que podem ser formados acompanhados de suas ligações.

O objetivo do jogo é formar um conjunto de quatro cartas que caracterizem uma ligação química. A primeira carta corresponde ao tipo de ligação que é estabelecida (iônica ou covalente), a segunda e a terceira correspondem aos elementos que serão unidos pela ligação, enquanto que a quarta carta corresponde ao composto que é formado pela união dos elementos em questão (Figura 8). O jogo permite que sejam formadas tanto ligações iônicas quanto covalentes. 


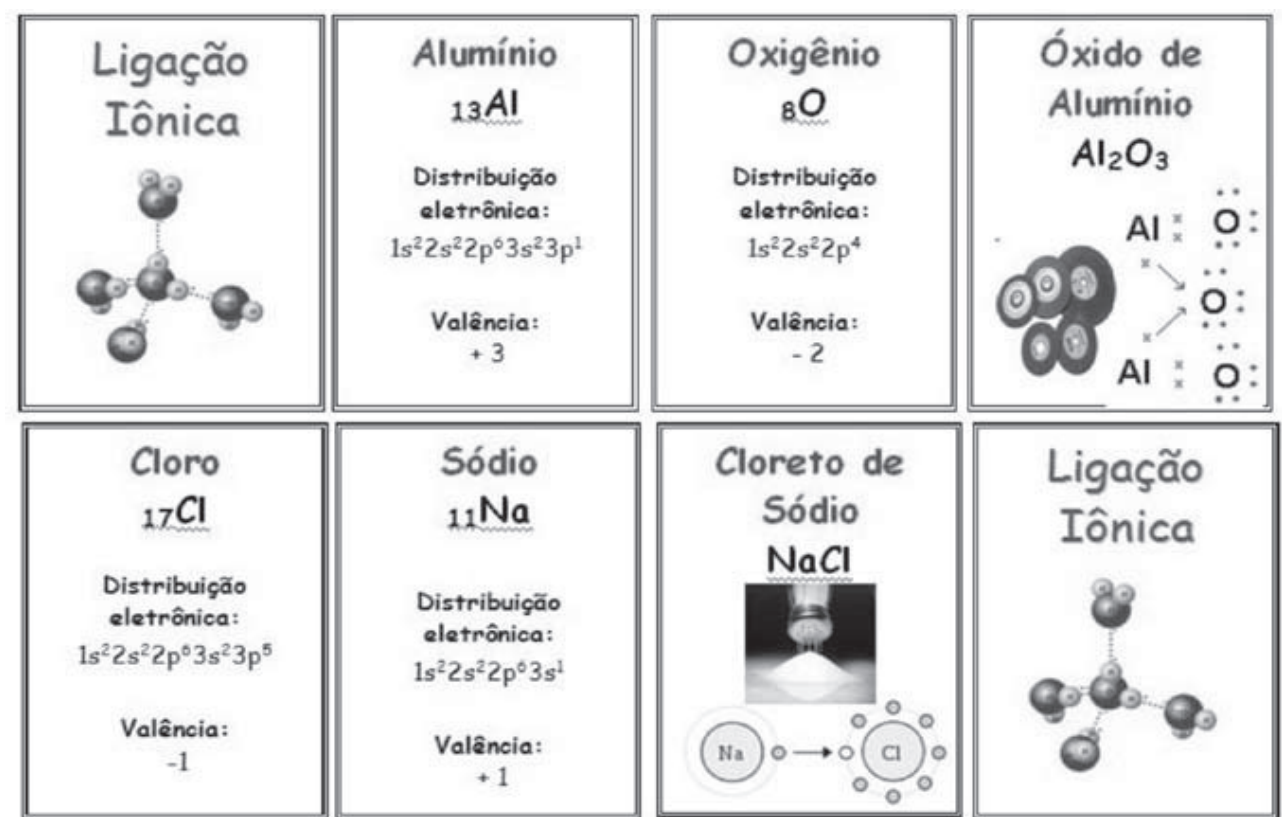

\section{Figura 8. Cartas do jogo “Ligações Químicas”}

O jogo funciona da seguinte forma: divide-se a sala em grupos de cinco a seis alunos. Cada jogador recebe quatro cartas do baralho e o restante das cartas é reservado em um monte para futuras "compras". Deve-se eleger o primeiro aluno a iniciar o jogo; ele deve iniciar comprando uma carta do monte; se ela for útil para formar a ligação, ele a mantém em mão e descarta na mesa outra carta que não seja útil (a carta fica "aberta"). Os outros jogadores continuam o jogo de acordo com a ordem estabelecida, devendo "comprar" ou descartar cartas que possibilitem a formação das ligações. Nesse jogo, o aluno sempre terá quatro cartas nas mãos e não deverá mostrá-las aos demais competidores; as cartas são reveladas apenas ao fim da partida. Cabe a cada jogador escolher qual ligação quer formar: se optar por formar ligação iônica, por exemplo, deverá encontrar as cartas que possibilitem a formação dessa ligação. Ganha o jogo o aluno que completar primeiro um conjunto correto de cartas que caracterize uma ligação química.

\section{Jogo: “Construindo com Funções Orgânicas"}

"Construindo com Funções Orgânicas" é um jogo composto por 70 cartas confeccionadas em papel vergê e plastificadas em papel 
contact. O baralho contém funções orgânicas (amida, amina, ácido carboxílico, aldeído, estér, éter, álcool e cetona); grupamentos químicos (carbono, hidrogênio, metila, etila, fenol e benzeno); e ligações (simples, duplas e triplas), como demonstrado na Figura 9.

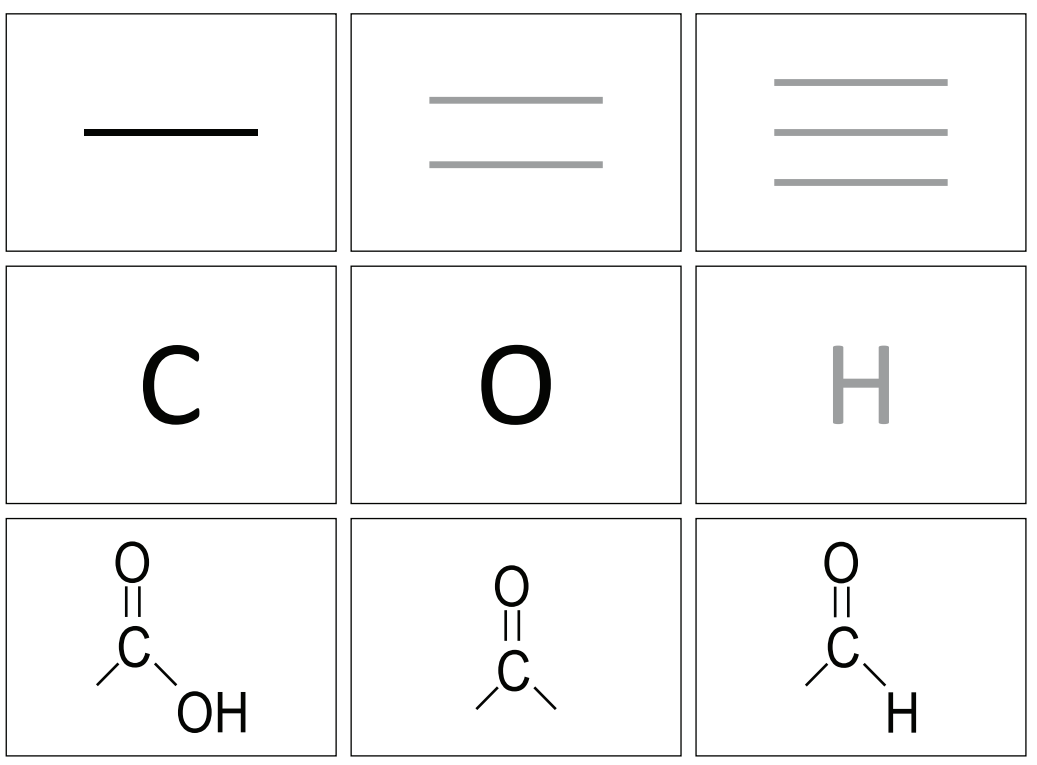

Figura 9. Cartas do jogo "Construindo com Funções Orgânicas”

A dinâmica do jogo consiste na formação de grupos que irão competir entre si. Assim, cada grupo deve ter o mesmo numero de integrantes e a mesma quantidade de cartas do baralho. Para cada resposta correta, são somados pontos ao grupo, que, no final do jogo, são contabilizados; ganha o grupo com maior pontuação.

A primeira etapa do jogo consiste na familiarização com as cartas e com a dinâmica do jogo; nessa fase, pede-se que os jogadores mostrem as funções orgânicas conforme Ihes é pedido. Por exemplo, pedia-se que mostrassem a carta que tivesse a função orgânica da cetona e o primeiro grupo que mostrasse essa carta obtinha cinco pontos em seu placar, seguido do segundo grupo que mostrasse a mesma carta, que obtinha três pontos.

A segunda etapa do jogo consiste em pedir aos jogadores que, utilizando as cartas, esquematizassem compostos orgânicos, a partir da nomenclatura IUPAC, explicitando a aplicação e a exemplificação de uso de um composto orgânico em seu cotidiano. A terceira etapa do jogo consiste em, por meio da fórmula molecular de um composto 
orgânico, colocar os jogadores para montar dois compostos isômeros e em seguida fornecer a nomenclatura IUPAC dos compostos.

Recebido em 31/08/2010

Recomendado pela Comissão em 13/07/2011

Aprovado em 23/11/2011

\section{Agradecimentos}

Ao programa de Bolsa de Iniciação à Docência (Pibid).

O presente trabalho foi realizado com o apoio da Capes, entidade do governo brasileiro voltada para a formação de recursos humanos.

\section{Referências bibliográficas}

BARROS, I. C. L.; SANTOS, V. O. Oficina de química: experimentos de química inorgânica para alunos do ensino médio. In: REUNIÃO ANUAL DA SOCIEDADE BRASILEIRA DE QUÍMICA,32., 2009, Fortaleza. Anais...

BOGDAN, R. C.; BIKLEN, S. K. Investigação qualitativa em educação matemática: uma introdução à teoria e aos métodos. Lisboa: Porto Editora, 1994.

BRANDES, D.; PHILLIPS, H. Manual de Jogos Educativos: 140 Jogos para Professores e Animadores de Grupo. Lisboa: Padrões Culturais, 1977.

BRASIL. Ministério da Educação e do Desporto - Secretaria de Ensino Fundamental. Parâmetros Curriculares Nacionais - Ciências Naturais Primeiro e Segundo Ciclos. Brasília: MEC/Semtec, 1996.

Ministério da Educação. Parâmetros Curriculares Nacionais:

Ensino Médio. In: MENEZES, L. C. (Coord.). Conhecimentos de Química. Ciências da Natureza, Matemática e suas Tecnologias - Parte III. Brasília: MEC/Semtec, 1999. 
BRASIL. Ministério da Educação. Orientações Curriculares para o Ensino Médio. Ciências da natureza, matemática e suas tecnologias. Brasília: MEC/Semtec, 2006, v. 2.

DEMO, P. Metodologia científica em Ciências Sociais. São Paulo: Atlas, 1995.

ELKONIN, D. Psicologia do jogo. São Paulo: Martins Fontes, 1998.

FREIRE, P. Pedagogia da anatomia. 30. ed. São Paulo: Paz e Terra, 2004.

FIALHO, N. Os Jogos Pedagógicos como Ferramentas de Ensino. In: CONGRESSO NACIONAL DE EDUCAÇÃO, 8., 2008, Curitiba, e CONGRESSO IBERO-AMERICANO DE VIOLÊNCIA NAS ESCOLAS, 3., 2008, Curitiba. Anais...

KISHIMOTO, T. M. Jogo, Brinquedo, Brincadeira e a Educação. São Paulo: Cortez, 1996.

LARA, I. C. M. Jogando com a matemática de $5^{\text {a a }} 8^{\text {a }}$ Série. São Paulo: Editora Rêspel, 2004.

LIMA, M. E. C. C. Formação continuada de professores de Química. Química Nova na Escola, n. 4, p. 12-17, nov. 1996.

LÔBO, S. F.; MORADILLO, E. F. Epistemologia e a formação docente. Química Nova na Escola, n. 17, p. 39-41, maio 2003.

LORETO, E. L. S.; SEPEL, L. M. N. Formação continuada de professores de biologia do ensino médio: atualização em genética e biologia molecular. Programa de incentivo à formação continuada de Professores do Ensino Médio. Universidade Federal de Santa Maria, 2006.

MENEZES, P. H. D. Tradição e Inovação no Ensino de Física: grupos colaborativos de professores dando estabilidade a mudanças. 2003. Monografia (Mestrado em Educação) - Faculdade de Educação, Universidade Federal de Minas Gerais, Belo Horizonte. 
MIRANDA, S. No fascínio do jogo, a alegria de aprender. Ciência Hoje, v. 28, p. 64-66, jan./fev. 2001.

PORLÁN, R.; RIVERO, A. El conocimiento de los profesores. Sevilla: Díada, 1998.

RAMOS, M. G. et al. A formação inicial de professores de Química na PUCRS: Um estudo de caso. In: ENCONTRO IBERO-AMERICANO DE COLETIVOS ESCOLARES E REDE DE PROFESSORES QUE FAZEM INVESTIGAÇÃO NA ESCOLA, 4., 2005, Lajeado.

ROSA, M. I. P.; ROSSI, A. V. Educação Química no Brasil: memórias, políticas e tendências. 1. ed. Campinas: Átomo, 2008.

SANTANA, E. M.; REZENDE, D. B. O uso de jogos no ensino e aprendizagem de química: Uma visão dos alunos do $9^{\circ}$ ano do Ensino fundamental. In: ENCONTRO NACIONAL DE ENSINO DE QUÍMICA, 14., 2008, Curitiba. Anais...

SANTOS, D. G. et al. Na Trilha da Reciclagem: um jogo didático para o auxílio da aprendizagem sobre a problemática do lixo. In: ENCONTRO CENTRO-OESTE DE DEBATES SOBRE ENSINO DE QUÍMICA, 16., 2009, Itumbiara. Anais...

SILVA, S. A.; OLIVEIRA, E. L. S. Estudo da Formação Continuada de Professores de Escolas Públicas Estaduais do Ensino Fundamental da $2^{\text {a }}$ fase e Ensino Médio em Jataí - GO. Revista eletrônica de Geografia do Campus Avançado de Jataí, n. 5, p. 1-21, jul./dez. 2005.

SILVEIRA, R. S.; BARONE, D. A. C. Jogos Educativos computadorizados utilizando a abordagem de algoritmos genéticos. 1998. Monografia (Pós-Graduação em Ciências da Computação) - Instituto de Informática, Universidade Federal do Rio Grande do Sul, Porto Alegre. Disponivel em: <http://www.c5.cl/ieinvestiga/actas/ribie98/151.html>. Acesso em: 29 nov. 2011.

SOARES, M. H. F. B. O lúdico em Química: jogos e atividades aplicados ao Ensino de Química. 2004. Tese (Doutorado em Química) - Departamento de Química, Universidade Federal de São Carlos, São Carlos. 
SOARES, M. H. F. B.; OKUMURA, F.; CAVALHEIRO, T. G. Proposta de um jogo didático para ensino do conceito de equilíbrio químico. Química Nova na Escola, n. 18, p. 13-17, nov. 2003.

VALENTE, A. L. Ação afirmativa, relações raciais e educação básica. Revista Brasileira de Educação, São Paulo, n. 28, p. 62-76, jan./abr. 2005.

VALENTE, J. A. Diferentes Usos do Computador na Educação. 1993. Disponivel em: <http://upf.tche.br/ carolina/pos/valente.html>. Acesso em: 31 ago. 2010. 